\title{
IN MEMORIAM PAUL KOKLA
}

Am 16. Mai dieses Jahres verstarb im 91. Lebensjahr unser großartiger Kollege, der angesehene Sprachwissenschaftler und Hochschullehrer Paul Kokla.

Paul Kokla war am 17. August 1929 in Kärdla auf der Insel Hiiumaa (Dagö) geboren worden. Nach dem Erlangen der mittleren Reife studierte er ab 1950 an der einst Staatlichen Universität Tartu (Dorpat) estnische Philologie und finnischugrische Sprachen. Sein fünfjähriges Studium schloss er mit einer Diplomarbeit über die Ableitungssuffixe der wepsischen Sprache ab, für die er das entsprechende Belegmaterial im Siedlungsgebiet der Wepsen selbst zusammengetragen hatte.

Seine erste Anstellung fand Paul Kokla in der Redaktion für finnischsprachige Sendungen des Estnischen Rundfunks. Da ihm aber die Sprachwissenschaft sehr am Herzen lag, ergriff er die sich nach zwei Jahren bietende Chance für die Aufnahme einer Aspirantur über die marische Sprache am finnisch-ugrischen Lehrstuhl der Universität Tartu (1957-1960), und anschließend wurde er in der Abteilung für finnisch-ugrische Sprachen im Institut für Sprache und Literatur in Tallinn angestellt. Im Mittelpunkt seiner 1964 verteidigten Dissertation, die leider nicht veröffentlicht wurde, standen die Possessivsuffixe der marischen Sprache. Er weilte mehrmals zu Feldforschungen in der Autonomen Sozialistischen Sowjetrepublik der Mari und verfasste auf Estnisch, Russisch und Deutsch sprachwissenschaftliche Artikel über deren Sprache, die beispielsweise den Possessivsuffixen -em und -et, den Postposi-

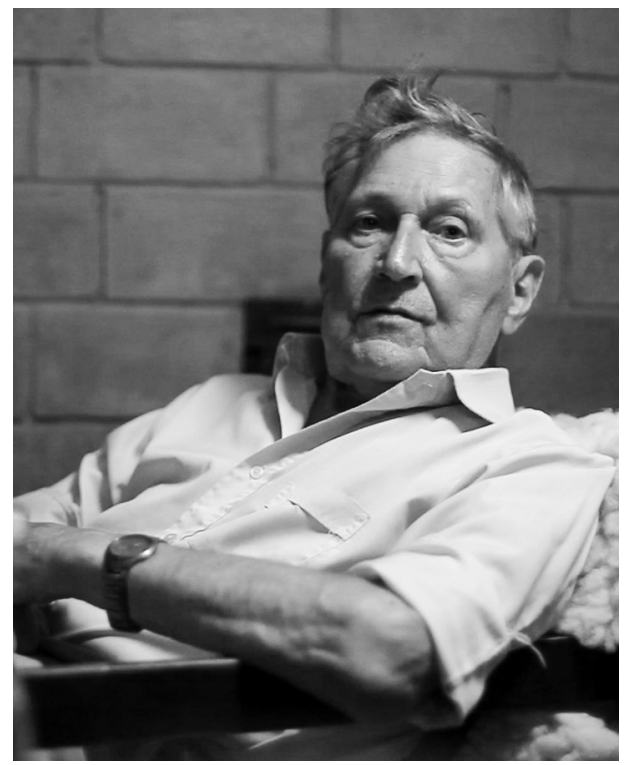

tionen und deren Verhältnis zu den Possessivsuffixen, der habeo-Konstruktion gewidmet waren ("Mari possessiivsufiksite -em, -et ajaloost ja esinemisest" (1961), "Postpositsioonidest mari keeles ja nende suhe possessiivsufiksitega" (1962), "Possessiiv- ja habeo-konstruktsioonid mari keeles" (1962), "Possessiivsufiksid mari keele substantiivides" (1963), "О притяжательных суффиксах в инфинитиве марийского языка" (1964), "Possessiivsufiksite esinemisest ja ajaloost mari keeles" (1964), "Zum Gebrauch der Pluralformen in der tscheremissischen possessiven Deklination” (1968), "Marilaste keel ja maa sugulase silmaga" (1970), "О системе падежей в первой грамматике марийского языка" (1977), "Инфинитная глагольная форма на $m \mathrm{~V}$ в марийском языке" (1977), "Zur 
Frage des tscheremissischen Kasussystems" (1979), "Zum Problem der Infinitive im Marischen" (1981), "mâla- ja šşlasufiksilised verbivormid mari keeles" (1986), "Das System der infiniten Formen im Marischen" (1986), "Унифицированная система описания диалектов в применении к коми и марийским глагольным формам" (1988), "Mari agentkonstruktsioonide morfoloogiline struktuur" (1988), "Einige morphonologische Probleme des Marischen" (1989), "Über die Möglichkeit einer einheitlichen marischen Schriftsprache" (1995), "Stammauslautende Vokale im PFU und der tscherimissische Vokalismus" (1996). In seinem Blickfeld lag das Rezensieren von Schriften über die Sprache der Mari und Werken marischer Sprachwissenschaftler. Gleichfalls trat er in deren Promotionsverfahren als Opponent auf.

In seinem Schaffen gibt es noch einige Aufsätze, in denen er sich mit Fragen anderer finnisch-ugrischer Sprachen befasste: "Mõnedest vepsa keele derivatsioonisufikseist" (1957), "О притяжательных суффиксах в личных местоимениях восточных финно-угорских языков" (1965), "Zum ostseefinnisch-permischen Lokalkasussystem" (1983).

Ein Jahr nach seiner Promotion nahm Paul Kokla 1965 als erste große Herausforderung das Erscheinen der neugegründeten sprachwissenschaftlichen Zeitschrift "Советское финно-угроведение - Sowjetische Finnisch-Ugrische Sprachwissenschaft - Finno-Ugric Studies" in Angriff - ab dem Jahr 1990 "Lingustica Uralica”. Er begleitete den Werdegang der Zeitschrift vom ersten Tag an, zunächst als Redakteur, nach dem Tod von Prof. Paul Ariste war er viele Jahre Chefredakteur und bis zu seinem Lebensende Mitglied des Redaktionskollegiums. Man konnte sich jeder Zeit an ihn wenden und sicher sein, dass er immer gute Ratschläge und Empfehlungen mitzuteilen hatte. Er gehörte zu den Personen, die die Struktur und das Profil der Zeitschrift gestalteten, und diese zur Tradition gewordenen Grundprinzipien bilden nun schon mehr als fünfzig Jahre das Fundament der redaktionellen Arbeit. Paul Kokla hat ebenso enorme Verdienste bei der Herausbildung der Autorenschaft, denn dank seiner ausgezeichneten Sprachkenntnisse und seinem ausgedehnten Bekanntenkreis ist es ihm gelungen, aus zahlreichen Ländern für unser Fachblatt neue Autoren zu gewinnen.

Paul Kokla war einer der Initiatoren für das Anlegen einer etymologischen Kartothek der estnischen Sprache sowie der erste Leiter dieser Arbeitsgruppe. Zu Beginn der Siebzigerjahre hat man in der Abteilung für finnisch-ugrische Sprachen des Instituts für Sprache und Literatur mit dieser umfangreichen Wörtersammlung begonnen und somit konnte er an der Wiege des Projektes stehend seinen Beitrag für das Erscheinen des etymologischen Wörterbuchs des Estnischen ("Eesti etümoloogiasõnaraamat", 2012) leisten. Mehr oder weniger sind mit der Vorarbeit für diese Publikation einige Artikel von Paul Kokla verbunden, in denen er sich unter anderem mit der Vergangenheit und Zukunft der etymologischen Forschung, mit Etymologie und Lexikografie auseinandersetzt ("Eesti keele etümoloogilise uurimise minevik ja tulevik", 1975; "Etümoloogia ja leksikograafia", 1977 und "Kontrastive Untersuchungen zur Übernahme internationaler Wörter im Estnischen, Finnischen und Ungarischen”, 1975) sowie seine Rezension über das Buch von R. Hinderling "Die deutsch-estnischen Lehnwortbeziehungen im Rahmen einer europäischen Lehnwortgeographie" (1982).

Paul Kokla offenbarte immer Interesse an Problemen, die mit der estnischen Schriftsprache und mit Schriftsprachen im weiteren Sinne im Zusammenhang standen. Bereits 1962 stellte er seine Standpunkte zum Estnischlehrbuch von Ö. Lavotha vor und später in den Achtzigern, aber vor allem in den Neunzigern verfasste er zu diesem Problemkreis einige Aufsätze, wie etwa "Zum Problem einer einheitlichen Schriftsprache" (1981), "Kielenuudistus ja kielensäätely viron kirjakielen kehittämismalleina" (1982), "Entstehung einer einheitlichen estnischen Schriftsprache" (1985), "Überlebensmöglichkeiten einer Sprache: Estland" (1993), "Staatssprache und Minderheitssprache 
(Die estnische Sprache zwischen Ost und West)" (1994), "Gondolatok az észt nép nemzeti ünnepén" (1994), "Eesti keele ja eestluse väljavaateid" (1996). Zudem redigierte er 1997 das Manuskript für das marischsprachige Estnischlehrbuch von Margarita Kuznetsova.

Der Dialekt seiner Heimat Hiiumaa trat im Wesentlichen erst im Ruhestand in den Fokus seines sprachwissenschaftlichen Wirkens und als dessen Ergebnis wurde 2015 das Wörterbuch "Hiiu sõnaraamat" publiziert, das im gleichen Jahr als bestes Druckerzeugnis in der Kategorie Sprache ausgezeichnet wurde.

Hohe Anerkennung verdient die Arbeit, die Paul Kokla für die Erstellung des estnisch-finnischen und finnisch-estnischen Wörterbuchs vollbracht hat. Im Jahre 1971 erschien in Finnland das Wörterbuch "Virolais-suomalainen sanakirja" und 1972 in der damaligen Estnische Sowjetrepublik "Eesti-soome sõnaraamat"; bei beiden Ausgaben fungierte er als Mitautor. Als logische Fortsetzung dieser Zusammenarbeit ist anzusehen, dass er auch in das Autorenkollektiv für die Erarbeitung des Gemeinschaftsprojekts des Instituts für estnische Sprache und des Forschungszentrums für Heimatsprachen Finnlands berufen wurde, und dieses große finnisch-estnische Wörterbuch ("Soome-eesti sõnaraamat") erblickte 2003 das Licht der Welt.

Eine bedeutende Rolle im Leben von Paul Kokla spielte seine Tätigkeit als Hochschullehrer, die in den Siebzigerjahren begann. Anfangs wirkte er als Lektor für Estnisch, später lehrte er auch die marische Sprache und finnischugrische Sprachwissenschaft. Von 1971 bis 1973 war er Gastlektor für Estnisch am finnisch-ugrischen Seminar der Universität Göttingen in der Bundesrepublik Deutschland. Im Frühjahrssemester 1972 belegte er parallel die gleiche Stelle an der Universität Hamburg. In den Jahren 1980-1982 weilte Paul Kokla in Finnland als Lektor für Estnisch an der Universität Turku und lehrte gleichzeitig im Herbstsemester an der Universität Helsinki die Grammatik der marischen Sprache. Für die Jahre 1992-1995 war Paul Kokla zum Leiter des Lehrstuhls für finnisch-ugrische Sprachen an der Universität Pécs in Ungarn gewählt worden und im Herbstsemester 1994 hatte er die Stelle eines Gastprofessors an der Katholischen Universität zu Budapest inne. Während seiner Tätigkeit in Ungarn fand ein weiteres bedeutendes Ereignis seines Lebens statt: Im Jahre 1996 hatte er an der Universität Szeged zum Doktor für Philosophie (PhD) promoviert. Im Frühjahr 1997 kehrte er nochmals an die Universität nach Hamburg zurück und lehrte ein Semester als Gastprofessor. Anschließend arbeitete er noch einige Jahre in der estnischen Hauptstadt als Dozent an der Pädagogischen Universität, der heutigen Universität Tallinn.

In der Zeit seines Wirkens an mehreren ausländischen Universitäten hat Paul Kokla sehr viel für Estland, vor allem für die Vermittlung der estnische Sprache und Kultur sowie für die Entwicklung von kulturellen und wissenschaftlichen Beziehungen geleistet. Bereits am Anfang seiner Arbeit als ausländische Lehrkraft schrieb er den Aufsatz "Einige Beziehungen der estnischen Kulturgeschichte zur Universität Göttingen” (1973) und während seines Aufenthaltes in Ungarn äußerte er sich über estnischungarische Kontakte im Bereich Kultur "Paar kildu eesti-ungari kultuurisuhetest" (1995).

Paul Kokla war Mitglied einiger wissenschaftlichen Gesellschaften: der hiesigen Gesellschaft für Muttersprache (Emakeele Selts), der Finnisch-Ugrischen Gesellschaft (Suomalais-Ugrilainen Seura, Helsinki), der Gesellschaft für finnische Sprache (Suomen Kielen Seura, Turku), der Gesellschaft für ungarische Sprachwissenschaft (Magyar Neylvtudományi Társaság, Budapest), der Societas Uralo-Altaica (Hamburg), der Internationalen Gesellschaft für ungarische Philologie (Nemzetközi Magyarságtudományi Társaság, Budapest). Weiterhin gehörte er dem Internationalen Komitee für die Finnougristik-Kongresse (ICFUC) und dem Estnischen Komitee der Finnougristik an. Er hat aktiv an den Kongressen, Symposien und Konferenzen dieses Fachgebiets teilgenommen. 
Für seine Arbeit und sein Engagement erhielt Paul Kokla hohe staatliche Auszeichnungen: im Jahre 1990 wurde er Verdienter Kulturschaffender der Estnischen SSR, 2010 ehrte ihn Finnland mit dem Ritterkreuz 1. Klasse des Ordens der Weißen Rose und 2015 erhielt er anlässlich des estnischen Nationalfeiertages den Orden des weißen Sterns V. Klasse.

Paul Kokla war es vergönnt, bis an sein Lebensende geistig aktiv zu sein. Gelegentlich schaute er in der Redaktion der Zeitschrift vorbei, und es war eine Freude seinen aufschlussreichen Anmerkungen und interessanten Gedanken über Sprach- und andere Probleme zu folgen. Paul Kokla wird als vielseitiger Sprachwissenschaftler und liebenswerter Kollege einen unauslöschlichen Platz in unseren Erinnerungen einnehmen. Seine letzte Ruhestätte hat er in seiner Geburtsstadt auf Hiiumaa gefunden.

$$
\text { VÄINO KLAUS (Tallinn) }
$$

A ddress

Väino Klaus

Linguistica Uralica

E-mail: lu@eki.ee 


\section{ESTONIAN ACADEMY PUBLISHERS}

\section{SUBSCRIPTION INFORMATION FOR THE YEAR 2020}

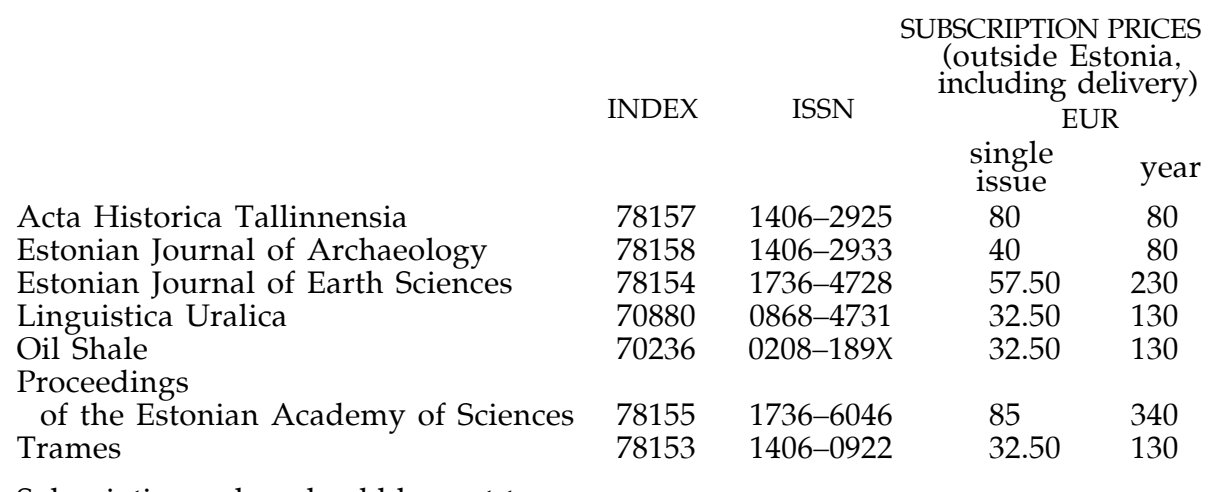

Subscription orders should be sent to:

Estonian Academy Publishers, Kohtu 6, 10130 Tallinn, Estonia

E-mail: silja.kala@akadeemia.ee

Советское финно-угроведение - Linguistica Uralica I-X 1965-1974.

Gesamtregister. Сводные указатели, Tallinn 1995

Советское финно-угроведение - Linguistica Uralica XI-XX 1975-1984.

Gesamtregister. Сводные указатели, Tallinn 2000

http://www.kirj.ee/public/Gesamtregister_1965-1984.pdf

\section{LINGUISTICA URALICA. SUPPLEMENTARY SERIES}

Volume 1. Estonian Language, Tallinn 2003; Second Edition, Tallinn 2007

Volume 2. Ilse Le h i s te, Pire Te ras, Toomas He l p, Pärtel Li p pus, Einar $M$ e i s t e r, Karl $P$ a j u s a 1 u, Tiit-Rein V i it s o, Meadow Mari Prosody, Tallinn 2005.

http://www.kirj.ee/public/va_lu/Meadow\%20Mari\%20Prosody.pdf

Volume 3. Eberhard W i n k 1 e r, Karl P a j u s a 1 u, Salis-livisches Wörterbuch, Tallinn 2009

Volume 4. Heinike H e i n s o o, Māja pūd lēväd, meid eb lēe. The Subject and the Predicate in Votic, Tallinn 2010 